\title{
Anemia and Transfusions in Surgical Patients: Current Concepts and Future Directions
}

Stefan W. Leichtle ${ }^{1}$, Nicolas J. Mouawad ${ }^{1}$ and Joseph J. Bander ${ }^{2}$

${ }^{1}$ Department of Surgery, Saint Joseph Mercy Health System, Ann Arbor, MI, USA

${ }^{2}$ Department of Surgical Critical Care, Saint Joseph Mercy Health System, Ann Arbor, MI, USA

\section{Summary}

Anemia is a frequent finding during routine assessment of patients prior to elective surgery. In this setting, anemia has been demonstrated to be a risk factor for negative post-operative outcomes as well as increased intra- and postoperative transfusion requirements.

Historically, blood products were given in abundance to surgical patients, based on liberal "transfusion triggers", i.e. mildly decreased hemoglobin or hematocrit levels prompted the transfusion of blood. Current guidelines propose a more restrictive approach for surgical patients, reflecting the increased recognition of complications of blood products beyond hemolytic transfusion reactions and disease transmission. Transfusionrelated acute lung injury, immunosuppression, alloimmunization, and even increased recurrence of malignancies have been associated with the administration of blood transfusions, and are of particular concern in the surgical population. Restoration of homeostasis and augmentation of oxygen delivery to tissues are the most common indications to administer blood products in surgical patients; their capability to achieve these goals, however, is rather limited.

A stronger focus on preoperative optimization of elective surgical patients, including earlier detection and treatment of anemia, along with increased efforts to minimize intraoperative blood loss may be the most promising strategies to avoid the complications associated with both anemia and blood products.

Keywords: Anemia; Transfusions; Blood products; Surgery; Oxygen delivery; Preoperative optimization

\section{Anemia in Surgery - Definition and Prevalence}

Half a century ago, a World Health Organization (WHO) study group on nutritional deficiencies defined anemia as hemoglobin levels less than $13 \mathrm{~g} / \mathrm{dL}$ in men and less than $12 \mathrm{~g} / \mathrm{dL}$ in women [1]. In the surgical literature, a wide variety of definitions for anemia have been used [2], which complicates the determination of its true prevalence, and makes interpretation and comparison of studies assessing anemia and outcomes difficult.

The prevalence of anemia in patients awaiting elective procedures may be widely underestimated. Depending on surgical subspecialty, it ranges from $30 \%$ in cardiovascular [3-5] and critically ill patients [6], to $76 \%$ in patients with advanced colon cancer [7]. The underlying cause of preoperative anemia often remains unclear $[2,8]$.

The strict definition of anemia based solely on hemoglobin values may be suitable for epidemiologic assessment purposes, but it is of limited value for clinical practice. Hemoglobin levels do not adequately reflect the amount of red blood cells in circulation. Rather, they are substantially determined by plasma volume [9], as impressively demonstrated with the significant changes of hematocrit values following postural changes in healthy subjects [10]. While this may be of lesser importance in chronic anemia, it is crucial for decision processes in critically ill patients, where fluctuations of plasma volume are frequent.

\section{Anemia in Surgery - Significance of the Problem}

The high prevalence of mild to moderate anemia found in asymptomatic patients awaiting elective surgery could suggest that preoperative anemia is more a laboratory than a clinically relevant finding. However, multiple studies have demonstrated that anemia in the preoperative setting indeed has significant clinical implications, and is more than just a marker of co-morbidities [5,11-18]. In patients who refuse blood products, a direct correlation was found between decreasing preoperative hemoglobin levels and increasing incidence of postoperative complications and rising mortality [12,13]. Large retrospective analyses have confirmed anemia as an independent risk factor for postoperative complications in general (non-cardiac) surgery $[11,12,14,15,17]$, as well as in high-risk cardiac and vascular surgery $[5,16,19]$.

Primary pathomechansim of anemia is a decrease of calculated oxygen delivery $\left(\mathrm{DO}_{2}\right)$ to tissue, with $\mathrm{DO}_{2}=\mathrm{CO} \times \mathrm{CaO}_{2}$ (CO: cardiac output; $\mathrm{CaO}_{2}$ : arterial oxygen content). With $\mathrm{CaO}_{2}=(\mathrm{Hgb} \times 1.34 \mathrm{x}$ $\left.\mathrm{SaO}_{2}\right)+\left(0.0031 \times \mathrm{PaO}_{2}\right)$ [Hgb: hemoglobin; $\mathrm{SaO}_{2}$ : arterial oxygen saturation; $\mathrm{PaO}_{2}$ : partial pressure of oxygen], the hemoglobin level is the most important determinant of $\mathrm{CaO}_{2}$.

A decrease in $\mathrm{DO}_{2}$ does not immediately lead to a compromise of oxygen consumption in peripheral tissue $\left(\mathrm{VO}_{2}\right)$, which remains stable secondary to two primary compensatory mechanisms: (1) an increase in the oxygen extraction ratio $\left(\mathrm{O}_{2} \mathrm{ER}\right)$, defined as $\left(\mathrm{SaO}_{2}-\mathrm{SvO}_{2}\right) / \mathrm{SaO}_{2}$

*Corresponding author: Stefan W. Leichtle, Saint Joseph Mercy Health System Department of Surgery 5333 McAuley Drive, Reichert Health Building R-211, Ann Arbor, MI 48106, Tel: (734) 846 - 1648; Fax: (734) 712 - 2809; E-mail: leichtls@ trinity-health.org

Received October 31, 2011; Accepted November 19, 2011; Published November 24, 2011

Citation: Leichtle SW, Mouawad NJ, Bander JJ (2011) Anemia and Transfusions in Surgical Patients: Current Concepts and Future Directions. J Hemato Thromb Dis S1:002. doi:10.4172/2155-9864.S1-002

Copyright: (c) 2011 Leichtle SW, et al. This is an open-access article distributed under the terms of the Creative Commons Attribution License, which permits unrestricted use, distribution, and reproduction in any medium, provided the original author and source are credited. 
$\left(\mathrm{SvO}_{2}\right.$ : venous oxygen saturation), and (2) an increase of CO. The latter can be well tolerated by healthy subjects [20,21], but patients without sufficient cardiac reserve, particularly the elderly, may not be able to employ this compensatory mechanism. Moreover, increases in stroke volume and heart rate to raise $\mathrm{CO}$ are accompanied by increases in myocardial oxygen consumption, potentially exacerbating pre-existing compromised flow dynamics, thus leading to ischemia, and possibly explaining the higher rate of cardiac complications and death in anemic patients.

\section{Complications of Blood Transfusions in Surgical Patients}

Traditionally, blood products were given in abundance to surgical patients based on liberal "transfusion triggers", i.e. even mildly decreased hemoglobin or hematocrit levels prompted the transfusion of blood products. These levels used to initiate transfusions were often more arbitrary, or institution-, rather than evidence-based. Surgeons' views on anemia and blood transfusions, however, have undergone significant changes in the last decade, and current transfusion guidelines propose a more restrictive approach [22].

One of the most recent official sources of information about national trends in of blood product utilization is "The 2009 National Blood Collection and Utilization Survey Report" issued by The United States Department of Health and Human Services [23]. In 2008, 15 million red blood cell transfusions (RBCs) were given in the U.S; surgical specialties (general, orthopedic, and cardiac surgery combined) had the second highest use of transfusions (23.6\% of all RBCs used per hospital in 2008; General Medicine: 28.2\%). Transfusion reactions that required further diagnostic or therapeutic interventions were reported in 60,110 of the more than 23 million units of blood products transfused in 2008, including RBCs, plasma, and platelets. Adverse reactions of blood products reported to the Transfusion Service are illustrated in Figure 1.

Modern surveillance systems and advanced testing methods have substantially reduced the number of complications of blood products, but they do remain a potentially serious threat. In addition to febrile and hemolytic transfusion reactions, and the potential transmission of infectious diseases, some adverse effects of blood products are of particular concern in surgical patients.

Transfusion-related acute lung injury (TRALI), characterized by dyspnea and hypoxia within hours of blood product administration,

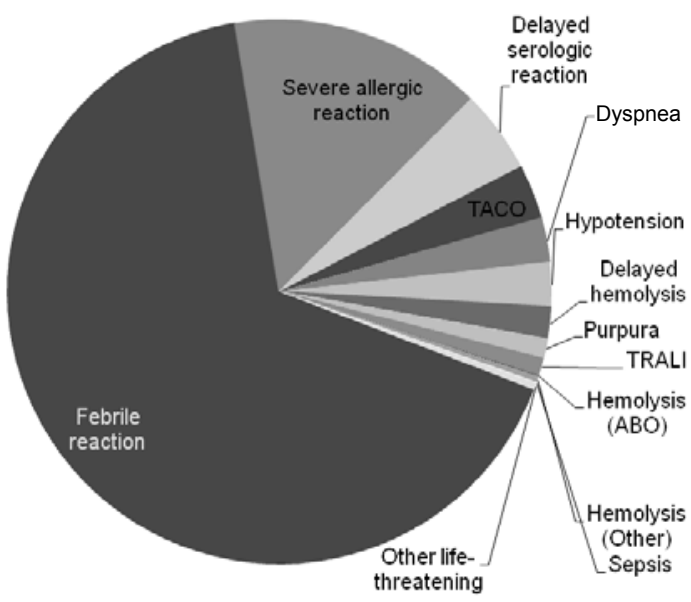

Figure 1: Adverse reactions to blood transfusions (TACO: Transfusionassociated circulatory overload; TRALI: Transfusion-related acute lung injury) based on the 2009 National Blood Collection and Utilization Survey Report [23] presents similar to acute respiratory distress syndrome (ARDS) with diffuse pulmonary infiltrates on chest radiography, or may be mistaken for cardiogenic pulmonary edema typical of fluid overload. The suggested pathomechanism is leukocyte sequestration in the pulmonary vasculature, and donor-related factors and antibodies were found to have a significant effect on the incidence of this complication [24].

In fact, TRALI is considered to be associated with plasma from female donors containing antibodies secondary to alloimmunization during pregnancy. Exclusion of female plasma donors in the United Kingdom resulted in a significant decrease of TRALI [25] and a recommendation to exclude female plasma donors was also introduced in the U.S. in 2006 [26]. An extremely low rate of TRALI $(1$ in 51,443) was reported in the 2009 National Blood Collection and Utilization Survey Report [23], but other contemporary studies suggest that TRALI is still a significant problem in up to $2.4 \%$ of cardiac surgery patients [27]. TRALI can occur with the transfusion of any blood product, and treatment is primarily supportive, with a mortality rate of up to $10 \%$.

The immunosuppressive effect of blood transfusions was impressively demonstrated by the use of blood transfusions for immunosuppression after kidney transplants decades ago [28], and has been confirmed by more recent results [29]. This effect not only explains the increased susceptibility of transfused patients to nosocomial infections [30], but might also be responsible for a concerning association of blood transfusions and malignancy.

Increased recurrence rates after curative resections of colon cancer in patients who received blood transfusions were initially suggested almost three decades ago [31], and a more recent randomized controlled trial comparing autologous versus allogenic blood transfusions also demonstrated lower long-term survival and higher recurrence of colon cancer in patients who received blood transfusions [32]. A large meta-analysis summarizing the many heterogenous studies on this topic affirmed the concern that perioperative transfusions may increase recurrence rates after curative resections for colon cancer significantly with OR $=1.42 ; 95 \%$ CI, $1.20-1.67$ [33]. This metaanalysis also demonstrated a dose-dependent relationship between blood transfusions and the risk for cancer recurrence, with odds ratios ranging from $1.40(95 \% \mathrm{CI}, 1.18$ - 1.67) after transfusion of one to two units of blood, to 1.69 (95\% CI, $1.40-2.03$ ) and 2.02 (95\% CI, 1.65 2.48 ) with the transfusion of three to four, and five or more units of blood, respectively.

Additionally, higher nosocomial infection rates [30,34], increased mortality and longer hospital stays were demonstrated in critically ill patients [35,36]; and more frequent postoperative complications and higher mortality rates were found after coronary artery bypass graft (CABG) [37] and colorectal operations during which blood products were transfused $[18,32]$.

\section{Utilization of Blood Transfusions in Surgical Patients}

Approximately $50 \%$ of patients in intensive care units receive at least one blood transfusion during their hospital stay $[38,39]$. Perioperative transfusions are given in $36 \%$ of pancreaticoduodenectomies, and in up to $84 \%$ of abdominal aortic aneurysm repairs [40].

Blood transfusions are commonly given to augment $\mathrm{DO}_{2}$ in patients with decreased hemoglobin levels and low physiologic reserve. One unit of RBCs can raise hemoglobin levels by approximately $1 \mathrm{~g} / \mathrm{dL}$, but this hemoglobin increase is not consistently associated with improvement of oxygen delivery or oxygen consumption [41,42]. Packed red blood 
cells represent an inferior substitute of whole blood, as reflected by the significantly altered properties of RBCs used for transfusion purposes.

Stored properly, RBCs may be used for up to 42 days. Over time, however, they acquire storage lesions, marked by decreases in $\mathrm{pH}$ and ATP, and increases in lactic acid, potassium and ammonia levels. Depletion of 2,3-DPG causes a left shift of the oxygen dissociation curve $[43,44]$, and the ability of RBCs to deliver oxygen to peripheral tissue becomes substantially impaired. Additionally, levels of proinflammatory cytokines rise over time, and the transfusion of older $\mathrm{RBCs}$ is associated with worse outcomes $[45,46]$. Usually, RBCs stored the longest are utilized first, with transfused RBCs being on average 18 days old [23]. Older RBC's, which may not be able to deform, may cause tissue ischemia and lactic acidosis by occlusion of capillaries [41].

In summary blood transfusions are only of limited efficacy in restoring oxygen delivery to tissue, are not capable of restoring normal blood physiology, and are not without significant associated complications.

A different trend seems to emerge in the setting of trauma and acute traumatic hemorrhage, where the previously propagated concept of aggressive crystalloid resuscitation gets increasingly replaced by reliance on blood products, primarily based on the experience with massive transfusion protocols in the recent wars in Iraq and Afghanistan. In this setting, the early use of plasma and RBCs, preferably in high FFP: RBC ratio, has been demonstrated to achieve superior outcomes [47-49].

\section{Recommendations for the Use of Blood Transfusions}

Evidence to restrict blood transfusions comes from a series of randomized controlled trials in cardiac surgery and critically ill patients. The Transfusion Requirements in Critical Care (TRICC) trial has caused a paradigm shift in the view of anemia and transfusions in critically ill patients [50]. A large randomized controlled trial in 25 Canadian intensive care units, the TRICC trial demonstrated that a restrictive transfusion strategy with goal hemoglobin levels of more than $7 \mathrm{~g} / \mathrm{dL}$ was not associated with higher 30-day mortality than a liberal transfusion strategy with goal hemoglobin levels of more than $10 \mathrm{~g} / \mathrm{dL}$. Moreover, the restrictive transfusion strategy proved to be beneficial for younger and healthier patients with age less than 55 years and APACHE II scores of less than 20, respectively.

A clinical trial in patients undergoing CABG surgery also demonstrated that a liberal transfusion strategy, triggering blood product administration if hemoglobin levels fell below $9 \mathrm{~g} / \mathrm{dL}$ did not confer any advantage over a more restrictive strategy that only allowed for blood transfusions if hemoglobin levels fell below $8 \mathrm{~g} / \mathrm{dL}$ [51].

Additional support for restrictive transfusion triggers came from the Transfusion Requirements after Cardiac Surgery (TRACS) trial. It demonstrated the non-inferiority of a restrictive transfusion strategy with a goal hematocrit $\geq 24 \%$ compared to a liberal transfusion strategy prompting administration of blood products to achieve a goal hematocrit $\geq 30 \%$ in high-risk surgical patients who had undergone cardiopulmonary bypass operations [52].

Based on these and other similar findings, current guidelines for trauma patients affirm the role of RBCs in the acute resuscitation of patients in hemorrhagic shock, but also emphasize the safety of restrictive transfusion strategies even in high-risk patients with stable cardiac disease, or on mechanical ventilation. "Transfusion triggers" based on absolute hemoglobin or hematocrit levels should therefore be considered an obsolete concept.
In addition to more general transfusion guidelines that can assist in the selection of patients that would most likely benefit from blood products [34], a promising, and novel approach may be the concept of "physiologic" transfusion triggers such as $\mathrm{O}_{2}$ ER. Defined as the ratio of $\mathrm{VO}_{2}$ and $\mathrm{DO}_{2}\left(\mathrm{O}_{2} \mathrm{ER}=\mathrm{VO}_{2} / \mathrm{DO}_{2}\right), \mathrm{O}_{2} \mathrm{ER}$ increases in reaction to declining $\mathrm{DO}_{2}$ in order to maintain $\mathrm{VO}_{2}$. Rearranging the equation $\mathrm{O}_{2} \mathrm{ER}=\mathrm{VO}_{2} / \mathrm{DO}_{2}=\left[\mathrm{SaO}_{2}-\mathrm{SvO} 2\right] / \mathrm{SaO} 2=1-\mathrm{SvO}_{2}$, assuming $\mathrm{SaO}_{2}$ $=1$, oxygen extraction can be estimated based on $\mathrm{SvO}_{2}$ measurements [53]. In the intensive care unit setting, $\mathrm{ScvO}_{2}$ measurements are frequently available and can be used to approximate $\mathrm{SvO}_{2} \cdot \mathrm{O}_{2} \mathrm{ER}>$ $50 \%$ is generally considered a sign of impending exhaustion of this compensatory mechanism and impending decrease of $\mathrm{VO}_{2}$. This threshold might be used to consider the transfusion of RBC. In practice, a small observational study in cardiac surgery patients suggested less frequent and more appropriate blood utilization when adding $\mathrm{O}_{2} \mathrm{ER}$ as a guide for transfusions [54].

\section{Preoperative Optimization of Patients}

Early detection of anemia and intervention in the preoperative setting may avoid the negative consequences of both preoperative anemia and blood transfusions. While most elective operations no longer entail preoperative hospitalization and comprehensive laboratory testing, the preoperative office visit may offer the opportunity to detect potentially reversible or modifiable anemia.

Anemia secondary to nutritional deficiencies is common in the elderly [8], and evaluation for common causes such as iron or vitamin deficiency can be performed easily and cost-efficiently. Oral ferrous sulfate can be employed successfully in most cases of mild anemia, and intravenous supplementation can be used in more severe cases to raise hemoglobin levels by approximately 1-2 g/dL per three weeks of treatment [55]. Anemia due to cobalamin (vitamin B12) and folate deficiency also responds to replacement within approximately 10 days, but replacements might have to be given intravenously.

For more severe forms of anemia, as seen in patients with chronic disease and malignancies, erythropoietin (EPO) has been used successfully in many protocols. Several studies demonstrated substantial benefits with the use of EPO, including decreased transfusion requirements and lower mortality in critically ill patients and in patients with gastrointestinal cancer [56,57]. Beneficial effects were demonstrated with as little as a single dose of EPO and iron one day prior to cardiac surgery in a recent study [58]. The enthusiasm for the use of EPO, however, has been curbed by inconsistent success with EPO [59], and by serious concerns about the adverse effects of EPO. These include an increased risk for thrombosis and stroke [54], and a potentially direct stimulating effect of EPO on tumor cell growth $[60,61]$.

\section{Blood Conservation Strategies}

Valuable lessons about preoperative optimization and intraoperative blood conservation can also be learned from the treatment of patients who refuse blood products. In addition to the administration of iron and EPO, these patients are frequently subjected to maximally bloodsaving techniques in the operating room. Hypotensive anesthesia and utilization of blood salvage were demonstrated to successfully minimize blood loss in spine surgery [62], and strict blood conservation strategies can help to maintain normal hematocrit levels even after major heart surgery [63].

Some strategies employed in these patient groups may be associated with additional complications and risks (e.g. EPO administration, 
hypotensive anesthesia), and are certainly not routinely applicable to all surgical patients. However, the success of intraoperative blood saving techniques indicates the potential for improvement with regard to hemostasis in many operations.

Most importantly, effective measures can be as safe and simple as judicious utilization of postoperative blood draws, by avoiding "routine" laboratory studies and using pediatric tubes if necessary.

\section{Conclusion}

Preoperative anemia in surgical patients represents a challenge that is most likely underappreciated in both its incidence and potential for harm. Blood transfusions are an effective means of resuscitation in the context of trauma and acute hemorrhage, but should not be considered a viable, routine treatment strategy for anemia. Awareness of these considerations is essential to improve patient outcomes. Preoperative optimization of elective surgical patients and utilization of blood saving techniques intraoperatively may be the most promising strategies to address these challenges.

\section{References}

1. WHO. Nutritional anaemias. Report of a WHO scientific group (1968) World Health Organ Tech Rep Ser

2. Shander A, Knight K, Thurer R, Adamson J, Spence R (2004) Prevalence and outcomes of anemia in surgery: a systematic review of the literature. Am J Med 116: 58S-69S.

3. Kulier A (2007) Anemia and morbidity and mortality in coronary bypass surgery. Curr Opin Anaesthesiol 20: 57-64.

4. Bell ML, Grunwald GK, Baltz JH, McDonald GO, Bell MR, et al. (2008) Does preoperative hemoglobin independently predict short-term outcomes after coronary artery bypass graft surgery? Ann Thorac Surg 86: 1415-1423.

5. Dunkelgrun M, Hoeks SE, Welten GM, Vidakovic R, Winkel TA, et al. (2008) Anemia as an independent predictor of perioperative and long-term cardiovascular outcome in patients scheduled for elective vascular surgery. Am J Cardiol 101: 1196-2000

6. Vincent JL, Baron JF, Reinhart K, Gattinoni L, Thijs L, et al. (2002) Anemia and blood transfusion in critically ill patients. JAMA 288: 1499-1507.

7. Cappell MS, Goldberg ES (1992) The relationship between the clinical presentation and spread of colon cancer in 315 consecutive patients. A significant trend of earlier cancer detection from 1982 through 1988 at a university hospital. J Clin Gastroenterol 14: 227-235.

8. Guralnik JM, Eisenstaedt RS, Ferrucci L, Klein HG, Woodman RC (2004) Prevalence of anemia in persons 65 years and older in the United States: evidence for a high rate of unexplained anemia. Blood 104: 2263-2268.

9. Jones JG, Holland BM, Hudson IR, Wardrop CA (1990) Total circulating red cells versus haematocrit as the primary descriptor of oxygen transport by the blood. Br J Haematol 76: 288-294.

10. Jacob G, Raj SR, Ketch T, Pavlin B, Biaggioni I, et al. (2005) Postura pseudoanemia: posture-dependent change in hematocrit. Mayo Clin Proc 80: 611-614.

11. Beattie WS, Karkouti K, Wijeysundera DN, Tait G (2009) Risk associated with preoperative anemia in noncardiac surgery: a single-center cohort study. Anesthesiology 110: 574-581.

12. Carson JL, Duff A, Poses RM, Berlin JA, Spence RK, et al. (1996) Effect of anaemia and cardiovascular disease on surgical mortality and morbidity. Lance 348: 1055-1060.

13. Carson JL, Poses RM, Spence RK, Bonavita G (1998) Severity of anaemia and operative mortality and morbidity. Lancet 1: 727-729.

14. Dunne JR, Malone D, Tracy JK, Gannon C, Napolitano LM (2002) Perioperative anemia: an independent risk factor for infection, mortality, and resource utilization in surgery. J Surg Res 102: 237-244.

15. Gruson KI, Aharonoff GB, Egol KA, Zuckerman JD, Koval KJ (2002) The relationship between admission hemoglobin level and outcome after hip fracture. J Orthop Trauma 16: 39-44.

16. Karkouti K, Wijeysundera DN, Beattie WS; Reducing Bleeding in Cardiac Surgery (RBC) Investigators (2008) Risk associated with preoperative anemia in cardiac surgery: a multicenter cohort study. Circulation 117: 478-484.

17. Wu WC, Schifftner TL, Henderson WG, Eaton CB, Poses RM, et al. (2007) Preoperative hematocrit levels and postoperative outcomes in older patients undergoing noncardiac surgery. JAMA 297: 2481-2488.

18. Leichtle SW, Mouawad NJ, Lampman R, Singal B, Cleary RK (2011) Does preoperative anemia adversely affect colon and rectal surgery outcomes? J Am Coll Surg 212: 187-194.

19. Zindrou D, Taylor KM, Bagger JP (2002) Preoperative haemoglobin concentration and mortality rate after coronary artery bypass surgery. Lancet 359: 1747-1748.

20. Weiskopf RB, Viele MK, Feiner J, Kelley S, Lieberman J, et al. (1998) Human cardiovascular and metabolic response to acute, severe isovolemic anemia. JAMA 279: 217-221.

21. Lieberman JA, Weiskopf RB, Kelley SD, Feiner J, Noorani M, et al. (2000) Critical oxygen delivery in conscious humans is less than $7.3 \mathrm{ml} \mathrm{O} 2 \times \mathrm{kg}(-1) \times$ $\min (-1)$. Anesthesiology 92: 407-413.

22. Napolitano LM, Kurek S, Luchette FA, Corwin HL, Barie PS, et al. (2009) Clinical practice guideline: red blood cell transfusion in adult trauma and critical care. Crit Care Med 37: 3124-3157.

23. Whitaker B, Schlumpf K, Schulman J, Green J (2011) The 2009 national blood collection and utilization survey report. Washington, DC: US Department of Health and Human Services, Office of the Assistant Secretary for Health.

24. Gajic O, Rana R, Winters JL, Yilmaz M, Mendez JL, et al. (2007) Transfusionrelated acute lung injury in the critically ill: prospective nested case-control study. Am J Respir Crit Care Med 176: 886-891.

25. Knowles S, Cohen H (2011) Serious Hazards of Transfusions (SHOT) Steering Group. The 2010 Annual SHOT Report

26. Vamvakas EC, Blajchman MA (2009) Transfusion-related mortality: the ongoing risks of allogeneic blood transfusion and the available strategies for their prevention. Blood 113: 3406-3417.

27. Vlaar AP, Hofstra JJ, Determann RM, Veelo DP, Paulus F, et al. (2011) The incidence, risk factors, and outcome of transfusion-related acute lung injury in a cohort of cardiac surgery patients: a prospective nested case-control study. Blood 117: 4218-4225.

28. Opelz G, Sengar DP, Mickey MR, Terasaki PI (1973) Effect of blood transfusions on subsequent kidney transplants. Transplant Proc 5: 253-259.

29. Opelz G, Vanrenterghem Y, Kirste G, Gray DW, Horsburgh T, et al. (1997) Prospective evaluation of pretransplant blood transfusions in cadaver kidney recipients. Transplantation 63: 964-967.

30. Taylor RW, Manganaro L, O'Brien J, Trottier SJ, Parkar N, et al. (2002) Impact of allogenic packed red blood cell transfusion on nosocomial infection rates in the critically ill patient. Crit Care Med 30: 2249-2254.

31. Burrows L, Tartter P (1982) Effect of blood transfusions on colonic malignancy recurrent rate. Lancet 2: 662.

32. Busch OR, Hop WC, Hoynck van Papendrecht MA, Marquet RL, Jeekel J (1993) Blood transfusions and prognosis in colorectal cancer. N Engl J Med 328: 13721376.

33. Amato A, Pescatori M (2006) Perioperative blood transfusions for the recurrence of colorectal cancer. Cochrane Database Syst Rev 25: CD005033.

34. Napolitano LM, Kurek S, Luchette FA, Anderson GL, Bard MR, et al. (2009) Clinical practice guideline: red blood cell transfusion in adult trauma and critical care. J Trauma 67: 1439-1442.

35. Zilberberg MD, Luippold RS, Sulsky S, Shorr AF (2008) Prolonged acute mechanical ventilation, hospital resource utilization, and mortality in the United States. Crit Care Med 36: 724-730.

36. Dasta J, Mody SH, McLaughlin T, Leblanc J, Shen Y, et al. (2008) Curren management of anemia in critically ill patients: analysis of a database of 139 hospitals. Am J Ther 15: 423-430

37. Koch CG, Li L, Duncan Al, Mihaljevic T, Cosgrove DM, et al. (2006) Morbidity and mortality risk associated with red blood cell and blood-component transfusion in 
Citation: Leichtle SW, Mouawad NJ, Bander JJ (2011) Anemia and Transfusions in Surgical Patients: Current Concepts and Future Directions. J Hematol Thromb Dis S1:002. doi:10.4172/2155-9864.S1-002

Page 5 of 5

isolated coronary artery bypass grafting. Crit Care Med 34: 1608-1616.

38. Corwin HL, Gettinger A, Pearl RG, Fink MP, Levy MM,et al. (2004) The CRIT Study: Anemia and blood transfusion in the critically ill--current clinical practice in the United States. Crit Care Med 32: 39-52.

39. Vincent JL, Piagnerelli M (2006) Transfusion in the intensive care unit. Crit Care Med 34: S96-S101.

40. www.acsnsqip.org, accessed 09/2011

41. Marik PE, Sibbald WJ (1993) Effect of stored-blood transfusion on oxygen delivery in patients with sepsis. JAMA 269: 3024-3029.

42. Creteur J, Neves AP, Vincent JL (2009) Near-infrared spectroscopy technique to evaluate the effects of red blood cell transfusion on tissue oxygenation. Crit Care 5: S11.

43. Ho J, Sibbald WJ, Chin-Yee IH (2003) Effects of storage on efficacy of red cell transfusion: when is it not safe? Crit Care Med 31: S687-S697.

44. Tinmouth A, Fergusson D, Yee IC, Hebert PC, ABLE Investigators; Canadian Critical Care Trials Group (2006) Clinical consequences of red cell storage in the critically ill. Transfusion 46: 2014-2027.

45. Vamvakas EC, Carven JH (1999) Transfusion and postoperative pneumonia in coronary artery bypass graft surgery: effect of the length of storage of transfused red cells. Transfusion 39: 701-710.

46. Koch CG, Li L, Sessler DI, Figueroa P, Hoeltge GA, Mihaljevic T, et al. (2008) Duration of red-cell storage and complications after cardiac surgery. $\mathrm{N}$ Engl J Med 358: 1229-1239.

47. Brown LM, Aro SO, Cohen MJ, Trauma Outcomes Group, Holcomb JB, et al. (2011) A high fresh frozen plasma: packed red blood cell transfusion ratio decreases mortality in all massively transfused trauma patients regardless of admission international normalized ratio. J Trauma 71: S358-S363.

48. Holcomb JB, Zarzabal LA, Michalek JE, Kozar RA, Spinella PC, et al. (2011) Increased platelet:RBC ratios are associated with improved survival after massive transfusion. J Trauma 71:S318-S328.

49. Cotton BA, Au BK, Nunez TC, Gunter OL, Robertson AM, et al. (2009) Predefined massive transfusion protocols are associated with a reduction in organ failure and postinjury complications. J Trauma 66: 41-48

50. Hebert PC, Wells G, Blajchman MA, Marshall J, Martin C, et al. (1999) A multicenter, randomized, controlled clinical trial of transfusion requirements in critical care. Transfusion Requirements in Critical Care Investigators, Canadian Critical Care Trials Group. N Engl J Med 340: 409-417.
51. Bracey AW, Radovancevic R, Riggs SA, Houston S, Cozart H, et al. (1999) Lowering the hemoglobin threshold for transfusion in coronary artery bypass procedures: effect on patient outcome. Transfusion 39: 1070-1077.

52. Haijar LA, Vincent JL, Galas FR, Nakamura RE, Silva CM,et al. (2010) Transfusion requirements after cardiac surgery: the TRACS randomized controlled trial. JAMA 304:1559-1567.

53. Vallet B, Robin E, Lebuffe G (2010) Venous oxygen saturation as a physiologic transfusion trigger. Crit Care 14: 213.

54. Orlov D, O'Farrell R, McCluskey SA, Carroll J, Poonawala H, et al. (2009) The clinical utility of an index of global oxygenation for guiding red blood cell transfusion in cardiac surgery. Transfusion 49: 682-688.

55. Auerbach M, Goodnough LT, Picard D, Maniatis A (2008) The role of intravenous iron in anemia management and transfusion avoidance. Transfusion 48: 9881000.

56. Corwin HL, Gettinger A, Pearl RG, Fink MP, Levy MM, et al. (2002) Efficacy of recombinant human erythropoietin in critically ill patients: a randomized controlled trial. JAMA 288: 2827-2835

57. Kosmadakis N, Messaris E, Maris A, Katsaragakis S, Leandros E,et al. (2003) Perioperative erythropoietin administration in patients with gastrointestinal tract cancer: prospective randomized double-blind study. Ann Surg 237: 417-421.

58. Yoo YC, Shim JK, Kim JC, Jo YY, Lee JH, Kwak YL (2011) Effect of single recombinant human erythropoietin injection on transfusion requirements in preoperatively anemic patients undergoing valvular heart surgery Anesthesiology 115: 929-937.

59. Corwin HL, Gettinger A, Fabian TC, May A, Pearl RG, et al. (2007) Efficacy and safety of epoetin alfa in critically ill patients. N Engl J Med 357: 965-976.

60. Pfeffer MA, Burdmann EA, Chen CY, Cooper ME, de Zeeuw D, et al. (2009) A trial of darbepoetin alfa in type 2 diabetes and chronic kidney disease. $\mathrm{N}$ Engl $\mathrm{J}$ Med 361: 2019-2032

61. Khuri FR (2007) Weighing the hazards of erythropoiesis stimulation in patients with cancer. N Engl J Med 356: 2445-2448.

62. Joseph SA, Jr., Berekashvili K, Mariller MM, Rivlin M, Sharma K, et al. (2008) Blood conservation techniques in spinal deformity surgery: a retrospective review of patients refusing blood transfusion. Spine 33: 2310-2315.

63. Rosengart TK, Helm RE, DeBois WJ, Garcia N, Krieger KH, et al. (1997) Open heart operations without transfusion using a multimodality blood conservation strategy in 50 Jehovah's Witness patients: implications for a "bloodless" surgical technique. J Am Coll Surg 184: 618-629.
This article was originally published in a special issue, Hematologic Oncology: Diagnosis \& Therapeutics handled by Editor(s). Dr. Ulrich Mahlknecht, Saarland University, Germany 